Fourth International Conference on Sustainable Construction Materials and Technologies http://www.claisse.info/Proceedings.htm

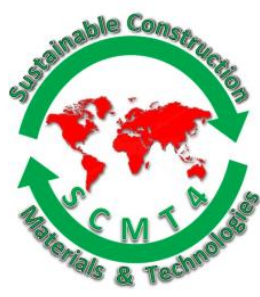

SCMT4

Las Vegas, USA, August 7-11, 2016

\title{
Effectiveness of FRCM System in Strengthening Reinforced Concrete Beams
}

\author{
Usama A. Ebead ${ }^{* 1 a}$, Kshitij C. Shrestha ${ }^{1 \mathrm{~b}}$, Muhammad S. Afzal ${ }^{1 \mathrm{c}}$, Ahmed El Refai ${ }^{2}$, and \\ Antonio Nanni ${ }^{3}$ \\ ${ }^{1}$ Department of Civil and Architectural Engineering, College of Engineering; Qatar University, P. $O$. \\ Box 2713, Doha, Qatar. \\ ${ }^{1 a}$ Email:<uebead@qu.edu.qa>, ${ }^{1 b}$ Email: <kshitij@qu.edu.qa>, ${ }^{1 c}$ Email: <shekaib@qu.edu.qa>. \\ ${ }^{2}$ Department of Civil and Water Engineering; Laval University, P. O. Box 4887, Quebec, Canada. \\ Email: 〈ahmed.elrefai@gci.ulaval.ca> \\ ${ }^{3}$ Department of Civil, Architectural, and Environmental Engineering; University of Miami, P. O. Box \\ 33146, Miami, FL, USA. Email: 〈nanni@miami.edu〉.
}

\begin{abstract}
In this paper, experimental work has been reported to investigate the efficiency of fiber-reinforced cementitious matrix (FRCM) in enhancing the flexural capacity and deformational characteristics of reinforced concrete (RC) beams. The aim of the experimental work is to assess the parameters that contribute to such enhancement. Twelve RC beam specimens, $2500 \mathrm{~mm}$ long, $150 \mathrm{~mm}$ wide and $260 \mathrm{~mm}$ deep, were prepared with two different reinforcement ratios of: $\rho_{\mathrm{s}}^{\mathrm{D} 12}=0.72 \%$ and $\rho_{\mathrm{s}}^{\mathrm{D} 16}=1.27 \%$, representing under-reinforced beam sections. The strengthened beams utilized two FRCM types; namely carbon and polyparaphenylene benzobisoxazole (PBO) FRCM systems. The RC beam specimens were tested in flexure under four-point loading until failure. Two beams without FRCM strengthening were used as control specimens. Six beams were externally reinforced by one, two and three layers of carbon FRCM system. Four beams were strengthened with one and two layers of PBO FRCM system. From the experimental observations, a reasonable gain in flexural strength was achieved for both the FRCM systems. Results showed that the flexural capacity of carbon FRCM strengthened beams (FRCM stiffness $=1422 \mathrm{MPa}$ ) can be increased by $78 \%$ and of PBO FRCM counterparts (stiffness $=605 \mathrm{MPa}$ ) by $27.5 \%$ over that of their control (un-strengthened) specimens.
\end{abstract}

\section{INTRODUCTION}

Extensive studies on strengthening of reinforced concrete (RC) structures in the past two decades have been largely limited to the application of fiber reinforced polymer (FRP) externally bonded (EB) with epoxy adhesives (Abdel Baky, Ebead, and Neale 2007; Aidoo, Harries, and Petrou 2006; Almassri et al. 2014; Barros and Fortes 2005; Capozucca 2014; Ebead and Saeed 2013; Ebead and Saeed 2014; Elsayed, Ebead, and Neale 2007; Elsayed, Ebead, and Neale 2009; Kotynia et al. 2008; Kreit et al. 2010; Neale et al. 2006; Teng et al. 2006; Ebead 2011). FRP strengthening technique with epoxy adhesives has several 
drawbacks, namely high costs, poor performance at high temperatures, and its inability to be installed on wet surfaces. A new strengthening technique has recently been introduced that uses fiber-reinforced cementitious matrix (FRCM) system for reinforced concrete structures (Arboleda et al. 2015; Babaeidarabad, Loreto, and Nanni 2014; Brückner, Ortlepp, and Curbach 2006; Loreto et al. 2015; Ombres 2011; Ombres 2015; Tetta, Koutas, and Bournas 2015; Trapko 2014; Triantafillou and Papanicolaou 2006). FRCM strengthening effectively addresses the above drawbacks and previous research studies have proven great success of FRCM in enhancing the performance of RC structures as external strengthening system. Unlike the conventionally epoxy bonded counterpart, this new technique utilizes inorganic cement-based mortar binders compatible to the original concrete substrate. Another advantage is that these systems utilize non corrosive fabric or textile reinforcement. More importantly, this is a viable repair/strengthening solution in the Gulf where extremely high temperatures, severe humidity, and high chloride content in soil and concrete materials can severely deteriorate the concrete and steel reinforcement.

The present work reports tests on a total of 12 medium-scale beam specimens under four-point loading. The beams are strengthened with two different types of FRCM systems and their feasibility will be studied for different strengthening schemes in comparison to the control beam specimens. The test matrix involves two different reinforcement ratios and several combinations for layers/plies of fabric. The work will contribute to the relatively limited research available on FRCM system for RC strengthening as compared to the EB FRP counterpart. In particular, the present study investigates comparison on effectiveness of different FRCM systems based on equivalent stiffness of the FRCM composite used. This will also be interesting to researchers and practitioners working in the strengthening field, particularly those in Qatar and in Gulf region where debonding of the EB FRP is a major concern, particularly due to severely high temperature ranges.

\section{EXPERIMENTAL INVESTIGATION}

\section{Materials}

Concrete. Ready mix concrete was used to cast the beam specimens. All the beams were cast using the same transit mixer at one time. For each cubic meter, the mixture proportions were $1,100 \mathrm{~kg}$ of gravel, $800 \mathrm{~kg}$ of sand, $370 \mathrm{~kg}$ of ordinary Portland cement. The water-to-cement ratio was kept at 0.45 .

Eight standard concrete cylinders with dimensions of $150 \mathrm{~mm}$ diameter and $300 \mathrm{~mm}$ height were used to evaluate the compressive strength of concrete. Also, six prisms of size $100 \times 100 \times 500 \mathrm{~mm}$ were tested to measure the flexural strength (modulus of rupture) of concrete. The samples were tested after five months from the day of casting representative of the beams which were also tested after four to six months of casting, after applying the appropriate FRCM strengthening techniques. Mean compressive strength of 67.5 MPa was recorded with standard deviation of 1.64 MPa. The concrete used has flexural strength of $9.63 \mathrm{MPa}$ with standard deviation of $0.62 \mathrm{MPa}$.

Reinforcing bars. Grade B (BS 4449:2005) steel bars were used as reinforcement in the construction of beams. Bars of diameter $8,12,16 \mathrm{~mm}$ were used. $8 \mathrm{~mm}$ diameter bars were used for all transverse steel reinforcement and also used in the compression reinforcement for all the beams, while 12 and $16 \mathrm{~mm}$ bars were used for the main flexural reinforcement. The yield stress and elastic modulus are $520 \mathrm{MPa}$ and 200 GPa, respectively.

Fiber-reinforced cementitious matrix (FRCM). Two commercially available FRCM systems have been utilized in this study, PBO fabric based and carbon fabric based. The first system uses of the PBO (polyparaphenylene benzobisoxazole) fabric based. The second system is the Carbon fabric based. Mortar 
mixes were prepared as per manufacturers' recommendations, $6.5 \mathrm{~L}$ water per $25 \mathrm{~kg}$ bag for the PBO system and $4 \mathrm{~L}$ water per $25 \mathrm{~kg}$ bag for the carbon system. 28-days compressive strength of PBO fabric associated mortar was $29.06 \mathrm{MPa}$ and carbon fabric associated mortar was $19.67 \mathrm{MPa}$. Table 1 reports mechanical properties of each fabric, provided by the manufacturer.

Further, FRCM test coupons $(410 \times 50 \times 10 \mathrm{~mm})$ were tested at 28 days' curing for characterization of tensile mechanical properties of each FRCM composites in accordance with AC434 (ICC 2013). Metal tabs (3 mm thick) were attached to the ends of test coupon using Sikadur30 epoxy with bond length of $150 \mathrm{~mm}$. Test was performed with monotonically applied uniaxial tensile load with a clevis-type anchor. Displacement control load was applied at a loading rate of $0.25 \mathrm{~mm} / \mathrm{min}$. The test results are presented in Table 2.

Table 1. Fabric geometric and mechanical properties (Adapted from manufacturers' data sheet).

\begin{tabular}{|c|c|c|c|c|}
\hline Fabric type & $\begin{array}{c}\text { Area per unit } \\
\text { width, } \\
A_{\mathrm{f}}\left(\mathrm{mm}^{2} / \mathrm{mm}\right)\end{array}$ & $\begin{array}{c}\text { Elastic } \\
\text { Modulus (GPa) }\end{array}$ & $\begin{array}{c}\text { Tensile } \\
\text { strength (GPa) }\end{array}$ & $\begin{array}{c}\text { Ultimate } \\
\text { strain (\%) }\end{array}$ \\
\hline PBO & 0.05 & 270 & 5.80 & 2.15 \\
\hline Carbon & 0.157 & 240 & 4.30 & 1.75 \\
\hline
\end{tabular}

Table 2. FRCM composite tensile characterization properties.

\begin{tabular}{|c|c|c|c|}
\hline $\begin{array}{c}\text { FRCM composite } \\
\text { type }\end{array}$ & $\begin{array}{c}\text { Elastic modulus of cracked } \\
\text { specimen, } E_{\mathrm{f}}(\mathrm{GPa})\end{array}$ & $\begin{array}{c}\text { Ultimate tensile } \\
\text { strength, } f_{\mathrm{fu}}(\mathrm{GPa})\end{array}$ & $\begin{array}{c}\text { Ultimate strain, } \\
\varepsilon_{\mathrm{fu}}(\%)\end{array}$ \\
\hline PBO & 121 & 2.59 & 2.30 \\
\hline Carbon & 151 & 2.10 & 1.25 \\
\hline
\end{tabular}

Test specimens. A total of 12 beam specimens (2500 mm long, 260mm deep and $150 \mathrm{~mm}$ wide) were tested in this research. The parameters investigated within these beams were: i) two different reinforcement ratios, ii) two different FRCM strengthening systems, and iii) number of fabric layers. Out of these, 2 beams were used as control specimens (not strengthened), one each with the main reinforcing bars (rebars) of $2 \mathrm{D} 12\left(\rho_{\mathrm{D} 12}^{\mathrm{s}}=0.72 \%\right)$ and $2 \mathrm{D} 16\left(\rho_{\mathrm{D} 16}^{\mathrm{s}}=1.27 \%\right)$ respectively. The effective depth of the beam was fixed at $210 \mathrm{~mm}$ for all the three types of beam specimens by differing the concrete cover at the bottom sides of 36 and $34 \mathrm{~mm}$ for 22 D12 and 2 D16 specimens respectively. The rest of 10 beams were strengthened with the adopted FRCM systems. 4 beams were strengthened with two different PBO-FRCM strengthening schemes (one and two layers). The remaining 6 beams are strengthened with three different Carbon-FRCM strengthening schemes (one, two and three layers).

The process of FRCM strengthening consisted of following steps: first the soffit of the beam was roughened/sandblasted to a level where the smooth outer layer cement was removed up to 2-3 mm depth and some fine aggregates were exposed. Next, the roughened beam was water saturated 30 minutes prior to applying the FRCM strengthening technique. For single-layer FRCM strengthening, the first layer of mortar matrix approximately $5 \mathrm{~mm}$ thick was laid on roughened soffit, followed immediately by impregnating one fabric layer in to the mortar layer with slight pressing. Next, the second layer of mortar matrix $5 \mathrm{~mm}$ thick was laid with final finishing. For multi-layer (two and three layer) FRCM system, similar laying procedures were followed with intermediate mortar layers of about 2-3 mm thick between each fabric layer. Figure 1 shows a typical FRCM strengthened beam specimen. 
Table 3 shows the test matrix where each strengthened specimen is identified using the " $X-Y-Z$ " nomenclature, where: " $X$ " denotes the FRCM strengthening scheme (C for Carbon and P for PBO); " $Y$ " denotes the main reinforcement bar ratio (RD12 for $\rho_{\mathrm{D} 12}^{\mathrm{S}}=0.72 \%$, and $\mathrm{RD} 16$ for $\rho_{\mathrm{D} 16}^{\mathrm{S}}=1.27 \%$ ); " $Z$ ' denotes the number of fabric layers (V1 for single layer, V2 for two layers, and V3 for three layers). The control or reference beams are represented by RD12 and RD16 representing respective main reinforcement ratios. Further, in Column 2 of Table 3, the amount of FRCM composite layers is also expressed in terms of equivalent stiffness for FRCM composite, $\kappa^{\mathrm{t}}$ given by, $\kappa^{\mathrm{t}}=n A_{\mathrm{f}} E_{\mathrm{f}} / b_{\mathrm{s}}$, where $A_{\mathrm{f}}$ is the equivalent area of each yarn of fabric per unit width (Table 1), $b_{\mathrm{s}}$ is width of the tensile characterization coupon sample, $n$ is the number of yarns of fabric within the width of the coupon sample and $E_{\mathrm{f}}$ is the cracked elastic modulus of the FRCM composite in $\mathrm{N} / \mathrm{mm}^{2}$ (Table 2). This parameter is important since $A_{\mathrm{f}}, n$ and $E_{\mathrm{f}}$ are different for carbon and PBO FRCM system, and comparison between the two FRCM systems will be made based on their $\kappa^{\mathrm{t}}$ values. Normalization of $\kappa^{\mathrm{t}}$ to single layer of carbon FRCM $(\boldsymbol{\kappa}=1422 \mathrm{MPa})$ gives following expressions for each FRCM system: $\boldsymbol{\kappa}$ for 1 layer of carbon, $2 \times \boldsymbol{\kappa}$ for 2 layers of carbon, $3 \times \boldsymbol{\kappa}$ for 3 layers of carbon, $0.42 \times \boldsymbol{\kappa}$ for 1 layer of PBO, and $0.85 \times \boldsymbol{\kappa}$ for 2 layers of PBO. The normalized values clearly suggest that, in the present study, equivalent stiffness for carbon FRCM composite is almost twice for the same number of layers for PBO FRCM composite.
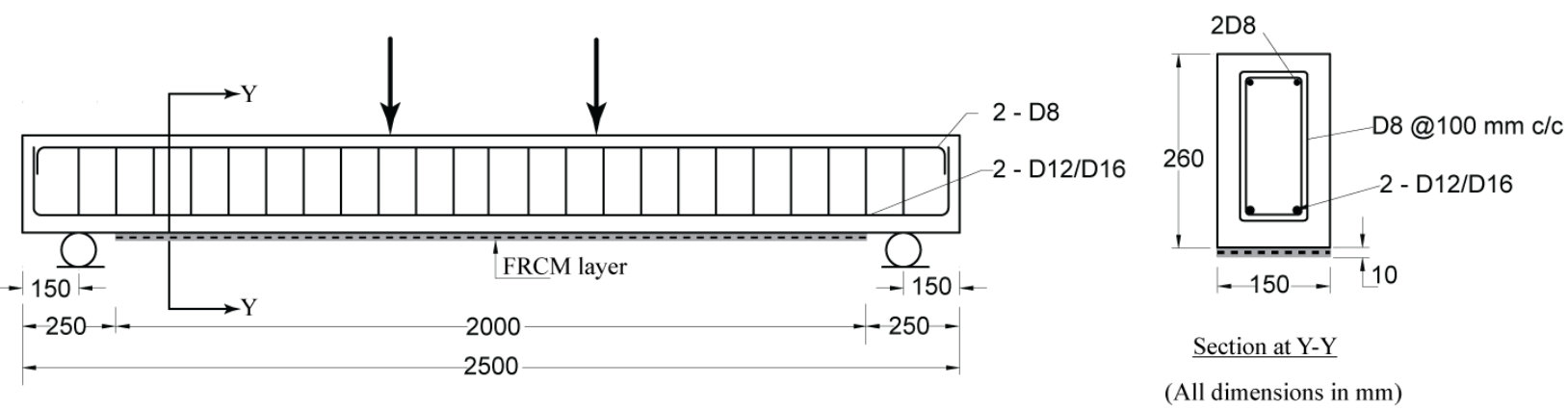

Figure 1. Details of typical FRCM strengthened beam specimen.

Test setup and instrumentation. The detail of the loading pattern with the four-point bending test adopted for all the specimens is illustrated in Figure 1. The test was performed under displacement control mode at a loading rate of $1 \mathrm{~mm} / \mathrm{min}$. Displacement measurements at the mid-span of the specimen were measured using displacement transducers. Two strain gauges were attached to the bottom rebars at the mid-span location and a concrete strain gauge was attached on the top of the concrete beam at mid-span location. Data acquisition of the measurements was performed at a frequency of $1 \mathrm{~Hz}$.

\section{RESULTS AND DISCUSSIONS}

The test results include the plots for load versus deflection, with ultimate load and deformation characteristics. Comparisons on ductility inde and energy dissipation for all the tested beams are made. The cracking patterns and failure mode characteristics are also discussed.

Table 3 shows the summary of results for all the test specimens. Columns 4 and 5 in Table 3 list the ultimate load carrying capacity $\left(P_{\mathbf{u}}\right)$ for each specimen and gain in $P_{\mathbf{u}}$ compared to the corresponding reference specimen. Ductility Index $(\Delta I)$ values for all the specimens are illustrated in Table 3, columns 6 and 7 respectively. Here, the ductility index $(\Delta I)$ is given by the ratio of the ultimate mid-span deflection $\left(\delta_{\mathrm{u}}\right)$ to the yield mid-span deflection $\left(\delta_{\mathrm{y}}\right)$. Here, $\delta_{\mathrm{u}}$ is smaller of either the largest deflection or the deflection at $20 \%$ drop in the ultimate load $\left(P_{\mathrm{u}}\right)$. And, $\delta_{\mathrm{y}}$ is the deflection at yielding of main steel rebars, evaluated based on the strain gauge reading of the bottom rebars, when the value of strain in rebars reaches $0.25 \%$. On the other hand, the energy absorption $(\Psi)$ is defined as the area under the load deflection curve up to the ultimate load. 
Load carrying capacity. Reference/Control beams. The ultimate loads recorded were $69.14 \mathrm{kN}$ and $110.32 \mathrm{kN}$ for RD12 and RD16 specimens, respectively. The failure patterns observed for all three reference beams were representative of conventional under-reinforced concrete beams, where rebar yielding resulted in the formation of wide flexural cracks near the mid span, followed by compression concrete crushing. Cracks along the concrete cover of main reinforcement rebars were also observed close to the final failure.

Table 3. Test matrix and summary of test results.

\begin{tabular}{|c|c|c|c|c|c|c|c|}
\hline Beam ID ${ }^{* 1}$ & $\begin{array}{c}\boldsymbol{\kappa}^{\mathrm{t}} \\
(\mathrm{MPa})\end{array}$ & $\begin{array}{c}\text { Normalized } \\
\kappa^{\mathrm{t}}\end{array}$ & $P_{\mathrm{u}}(\mathrm{kN})$ & $\begin{array}{c}\text { Gain in } P_{\mathrm{u}} \\
(\%)\end{array}$ & $\Delta I$ & $\begin{array}{c}\Psi \\
(\mathrm{kN}-\mathrm{mm})\end{array}$ & $\begin{array}{c}\text { Mode of failure } \\
\text { at } P_{\mathrm{u}}^{* 2}\end{array}$ \\
\hline RD12 & - & - & 69.14 & - & 5.81 & 2659 & SY+CC \\
\hline RD16 & - & - & 110.32 & - & 4.49 & 3681 & SY+CC \\
\hline C- RD12-V1 & 1422 & $\boldsymbol{\kappa}$ & 85.15 & 23.16 & 2.41 & 1210 & FS+FC \\
\hline C- RD12-V2 & 2845 & $2 \boldsymbol{\kappa}$ & 89.12 & 28.90 & 1.58 & 822 & FS+FC \\
\hline C- RD12-V3 & 4267 & $3 \boldsymbol{\kappa}$ & 122.71 & 77.48 & 2.95 & 2269 & FS+D \\
\hline C- RD16-V1 & 1422 & $\boldsymbol{K}$ & 126.17 & 14.37 & 2.03 & 1961 & FS+D \\
\hline C- RD16-V2 & 2845 & $2 \boldsymbol{\kappa}$ & 142.29 & 28.98 & 2.06 & 2027 & FS+D \\
\hline C- RD16-V3 & 4627 & $3 \boldsymbol{\kappa}$ & 161.93 & 46.78 & 2.46 & 2888 & FS+D \\
\hline P- RD12-V1 & 605 & $0.42 \boldsymbol{\kappa}$ & 84.68 & 22.48 & 4.16 & 2804 & FRCM(C+D) \\
\hline P- RD12-V2 & 1210 & $0.85 \boldsymbol{\kappa}$ & 88.15 & 27.49 & 4.09 & 2473 & FRCM(C+D) \\
\hline P- RD16-V1 & 605 & $0.42 \boldsymbol{\kappa}$ & 118.92 & 7.80 & 3.03 & 3007 & FRCM(C+D) \\
\hline P- RD16-V2 & 1210 & $0.85 \boldsymbol{\kappa}$ & 123.86 & 12.27 & 2.93 & 2943 & FRCM(C+D) \\
\hline
\end{tabular}

${ }^{*}{ }^{*}$ C represents Carbon-FRCM, $P$ represents PBO-FRCM; RD12 is for 2-D12, and RD16 is for 2-D16 main reinforcement; $V 1$ is for 1 layer, V2 for 2 layers, and V3 is for 3 layers of fabric

${ }^{* 2} S Y$ - steel yielding, CC - concrete crushing, FS - fabric slippage, FC - Flexural cracks, D-FRCM delamination, FRCM $(C+D)-$ Cracking plane within FRCM and FRCM delamination

Carbon fabric reinforced beams. Figure 2 (a) shows the load versus mid-span deflection plot for strengthened beams having D12 as main steel reinforcement. Significant gain in load carrying capacity was observed for the carbon FRCM system with gains in $P_{\mathrm{u}}$ of: C-RD12-V1 - 23\%, C-RD12-V2 - 29\%, and C-RD12-V3 - 77\%. Similarly, for main steel reinforcement D16, the load-deflection plots are shown in Figure 2 (b). The corresponding gains in ultimate load for the specimens were: C-RD16-V1 - 14\%, CRD16-V2 - 29\%, and C-RD16-V3 - 47\%. The observed cracking patterns are illustrated in Figure 3 for C-RD12-V2 and C-RD12-V3 as representative examples.
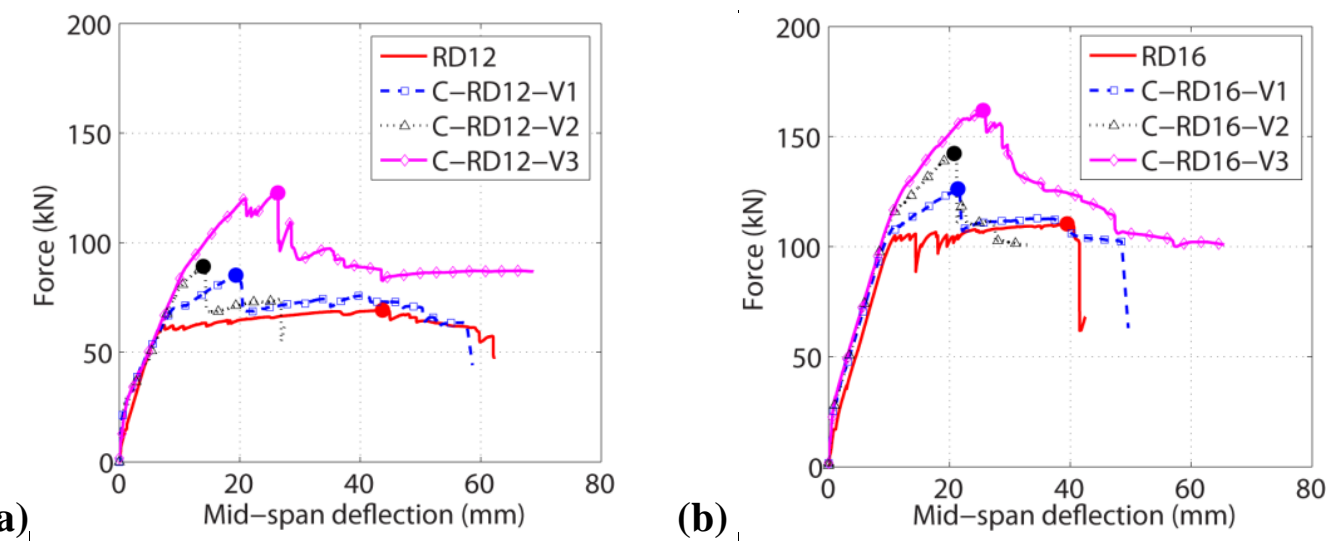

Figure 2. Load-deflection plots for Carbon FRCM strengthened specimens: (a) D12 specimens, (b) D16 specimens 

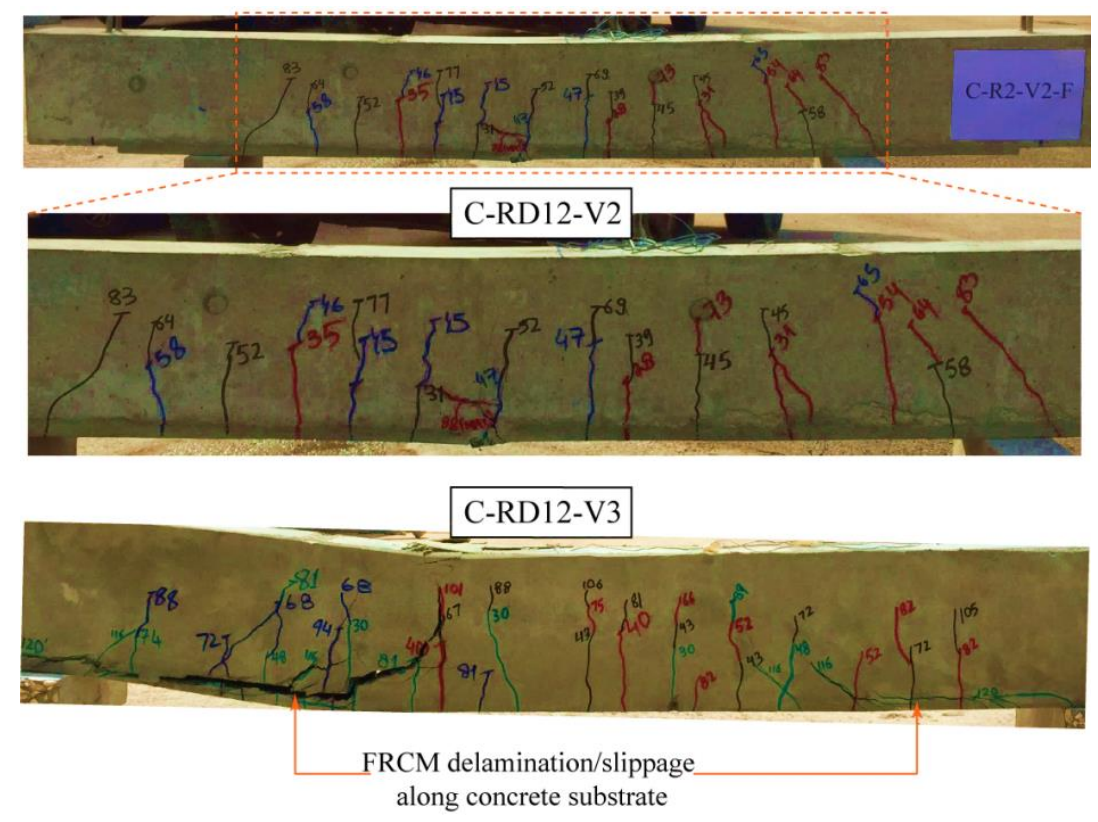

Figure 3. Crack patterns for specimens C-RD12-V1 and C-RD12-V3 (values in kN)

PBO fabric reinforced beams. Figures 4 (a) and (b) show the load versus mid-span deflection plots for PBO FRCM strengthened beams with D12 and D16 as main longitudinal steel reinforcement respectively. The observed gains in ultimate load, $P_{\mathrm{u}}$ were: [P-RD12-V1 - 22\%, P-RD12-V2 - 27\%] and [P-RD16-V1 $-8 \%$, P-RD16-V2 - 12\%] which also showed considerable increment in ultimate load compared to the control specimens. For brevity, the observed cracking pattern only for specimens P-RD12-V2 and PRD12-V2 are illustrated in Figure 5.

Both the FRCM systems performed effectively in strength enhancement of the respective control beams. Higher gains in $P_{\mathrm{u}}$ for carbon FRCM compared to PBO counterpart with same number of fabric layer was contributed by higher values of $\kappa^{\mathrm{t}}$ for carbon FRCM composite. Comparison on each strengthened beam on the basis of equivalent stiffness of FRCM composite is presented in Figure 6. Specimens C-RD12-V1 and P-RD12-V2 have normalized $\kappa^{\mathrm{t}}$ of $\boldsymbol{\kappa}$ and $0.85 \boldsymbol{\kappa}$ respectively and this was reflected in the ultimate loads recorded for each specimen of $85.15 \mathrm{kN}$ and $88.15 \mathrm{kN}$. Similar observations were made for specimens C-RD16-V1 and P-RD16-V2. The equivalent stiffness of FRCM composite, therefore, directly influences ultimate load carrying capacity of the strengthened beams.

Figur

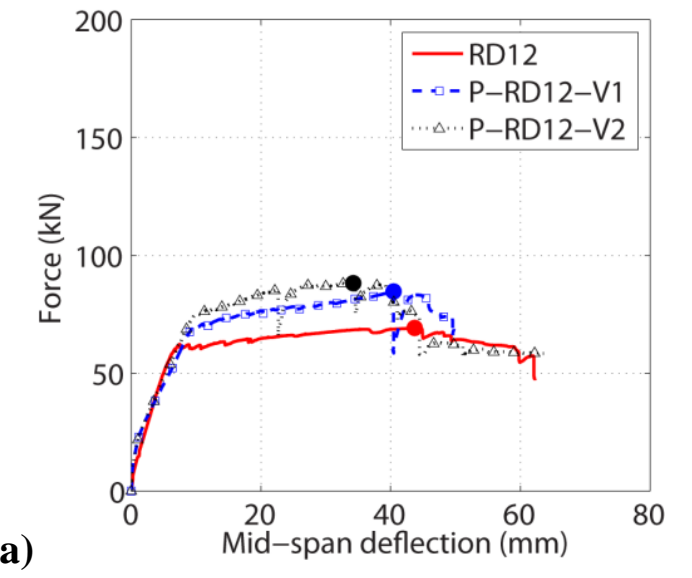

(b)

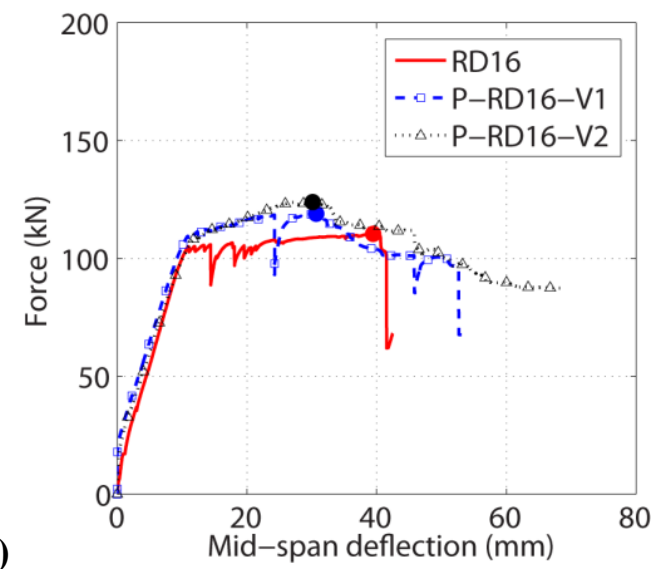

Figure 4. Load-deflection plots for PBO FRCM strengthened specimens: (a) D12 specimens, (b) D16 specimens 

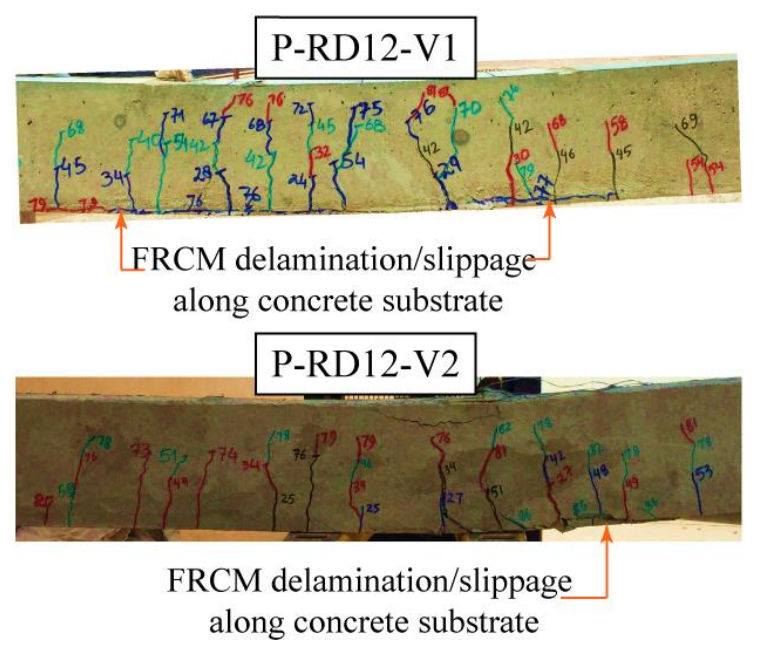

Figure 5. Crack patterns for specimens P-RD12-V1 and P-RD12-V2 (values in kN)

Ductility index and energy absorption characteristics. Column 6 in Table 3 summarizes the values of ductility index $(\Delta I)$, which is the ratio between the deflection at ultimate load to that at yield load, for all tested specimens. The reference beams RD12 and RD16 showed higher values of ductility indices characteristic of typical under-reinforced beam specimens. The ductility decreased with increase in percentage of main steel reinforcement. The FRCM strengthened beams showed relatively lower ductility as compared to the respective control beams, contributed by higher stiffness and strength characteristics of the strengthening FRCM layer. In general, the PBO strengthened specimens with equivalent stiffness $42 \%$ of the carbon counterparts for the same number of fabrics used, were more ductile. The average values of ductility indices of using carbon as strengthening material were $0.40 \times$ and $0.49 \times$ for D12 and D16 beam specimens respectively to that of the control specimen. Similarly, the average values of ductility indices of using PBO as strengthening material were $0.71 \times$ and $0.66 \times$ for D12 and D16 specimens to that of the respective control specimen.

Furthermore, the energy dissipation characteristics for the PBO strengthened beams were also comparatively superior to the carbon counterparts, contributed by the stiffness characteristics. The average values of the energy absorption in Carbon-FRCM strengthened beams were $54 \%$ and $62 \%$ of that of the respective control beams with reinforcement ratio $\rho_{\mathrm{s}}^{\mathrm{D} 12}=0.72 \%$ and $\rho_{\mathrm{s}}^{\mathrm{D} 16}=1.27 \%$, respectively. Similarly, the average values of the energy absorption in PBO-FRCM strengthened beams were $99 \%$ and $81 \%$ of that of the benchmark beams with reinforcement ratio $\rho_{\mathrm{s}}^{\mathrm{D} 12}=0.72 \%$ and $\rho_{\mathrm{s}}^{\mathrm{D} 16}=1.27 \%$, respectively.

Modes of failure. Summary of the modes of failure for all the specimens near the ultimate load is illustrated in Column 7 of Table 3. The control specimens showed mode of failure representative of typical under-reinforced beam section with large flexural cracks near mid-span due to steel yielding, and final failure mode with concrete crushing at the top mid-section of the beam. For the FRCM strengthened beams, the crack propagation and failure modes were defined by the type of FRCM system and the number of layers of fabric used. The modes of failures in the strengthened beams close to the ultimate load were either or combination of these: i) Mode 1: wide flexural cracks with extensive slippage of fabric within the mortar matrix, ii) Mode 2: FRCM delamination, or separation of FRCM layer from the concrete substrate. Concrete crushing was observed close to the final failure mode for majority of the specimens. The strain levels in concrete at the top mid-span section of all the beams, at the instant of ultimate load, was within the maximum allowable strain level in concrete $\left(\varepsilon_{\mathrm{cu}}=0.003\right)$. 
Figure 3 shows modes of failure for the selected carbon FRCM strengthened specimens. Carbon FRCM strengthened specimens, C-RD12-V1, C-RD12-V2, C-RD16-V1 and C-RD16-V2 showed Mode 1 failure, where large flexural cracks were observed throughout the length of the beam. The cracks originated from within the mid-span section of the beam and new cracks developed outside the mid-span section at higher load levels. More importantly, no cracks were observed within the FRCM layer along the length of the beam and extensive slippage of fabric was observed at the beam's soffit. For 3-layer carbon FRCM strengthened specimens, C-RD12-V3 and C-RD16-V3, the mode of failure changed to Mode 2 type. A clear observation of cracks along the length of FRCM layer was made, with separation of the whole FRCM layer from the concrete substrate. Close to the final failure, for all these beams, cracks along the main reinforcement concrete cover were also observed with crushing of concrete at the top mid-span section of the beam.
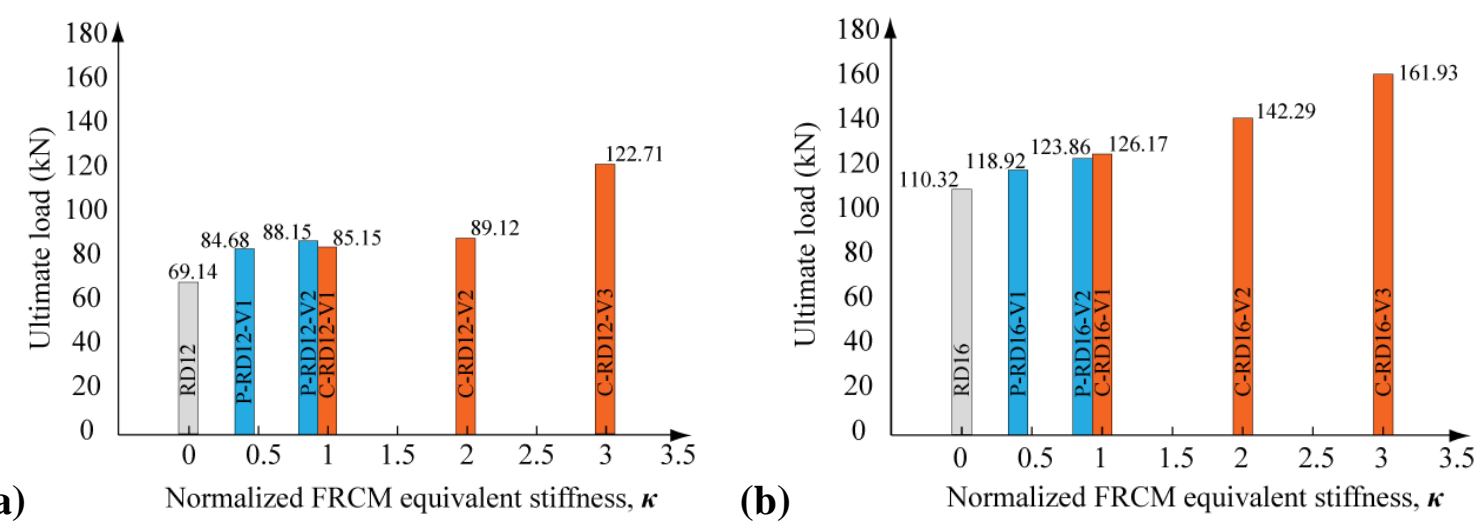

\section{Figure 6. Ultimate load versus normalized FRCM equivalent stiffness plots for: (a) RD12 specimens, and (b) RD16 specimens}

All PBO FRCM strengthened specimens (P-RD12-V1, P-RD12-V2, P-RD16-V1 and P-RD16-V2) in contrary showed similar modes of failure, with combination of Mode 1 and Mode 2, as illustrated in Figure 5. Origination of cracks started near mid-span section with vertical flexural cracks. At higher load levels, new vertical cracks appeared outside the two loading points. Extensive cracks within the FRCM layer were observed near the ultimate load value, with the cracks extending along the whole length of FRCM layer. Extensive PBO fabric slippage was also observed at the beam soffit with wide flexural cracks.

\section{CONCLUSION}

Extensive experimental works were done on 12 beams to study effectiveness of fabric reinforced mortar (FRCM) as strengthening technique. Beams with different main steel reinforcement ratios, strengthened with two different FRCM systems, carbon and PBO were studied. The number of layers/plies of fabrics were also varied in the tested specimens. The following general conclusions can be drawn from the reported experimental works:

- Both the FRCM systems, carbon and PBO, performed effectively in enhancing the ultimate load carrying capacity of the beam specimens. Increase in ultimate load was higher for specimens with higher number of layers of fabric. An average increment in load of $36 \%$ for carbon FRCM system and $18 \%$ for PBO FRCM system over that of their control (un-strengthened) specimens was observed.

- The equivalent stiffness of FRCM composite, $\kappa^{\mathrm{t}}$ directly influences ultimate load carrying capacity of the strengthened beams. For two different FRCM systems, with similar equivalent stiffness values 
gave approximately identical increase in ultimate load. This was observed for specimens i) C-RD12V1 and P-RD12-V2, and ii) C-RD16-V1 and P-RD16-V2.

- The modes of failure in beams strengthened with carbon FRCM were affected by the number of layers of carbon fabric used. For single and double layer of carbon fabric, fabric slippage from the mortar matrix was observed. However, for three layered carbon FRCM strengthened beam, slippage of the whole FRCM from the concrete substrate was observed. For all PBO FRCM strengthened beams, same mode was observed with slippage of fabric as well as FRCM delamination.

- PBO-FRCM strengthened beams showed more ductile behavior as compared to those strengthened with comparatively stiffer Carbon-FRCM systems. Average ductility indices were $45 \%$ and $69 \%$ of that of the corresponding unstrengthened beams for Carbon-FRCM and PBO-FRCM strengthened beams, respectively. An average energy absorption was 58\% and $90 \%$ of that of the unstrengthened beams for Carbon-FRCM and PBO-FRCM strengthened beams, respectively.

\section{ACKNOWLEDGEMENTS}

This paper was made possible by NPRP grant \# NPRP 7-1720-2-641 from the Qatar National Research Fund (a member of Qatar Foundation). The statements made herein are solely the responsibility of the authors.

\section{REFERENCES}

Abdel Baky, H. M., U. A. Ebead, and K. W. Neale. 2007. 'Flexural and interfacial behavior of FRPstrengthened reinforced concrete beams', ASCE Journal of Composites for Construction, 11: 629-39.

Aidoo, J., K. A. Harries, and M. F. Petrou. 2006. 'Full scale experimental investigation of repair of reinforced concrete interstate bridge using CFRP materials', ASCE Journal of Bridge Engineering, 11: $350-58$.

Almassri, B., A. Kreit, F. A. Mahmoud, and R. François. 2014. 'Mechanical behaviour of corroded RC beams strengthened by NSM CFRP rods', Composites Part B: Engineering, 64: 97-107.

Arboleda, D., F. G. Carozzi, A. Nanni, and C. Poggi. 2015. 'Testing Procedures for the Uniaxial Tensile Characterization of Fabric-Reinforced Cementitious Matrix Composites', ASCE Journal of Composites for Construction: 04015063.

Babaeidarabad, S., G. Loreto, and A. Nanni. 2014. 'Flexural Strengthening of RC Beams with an Externally Bonded Fabric-Reinforced Cementitious Matrix', ASCE Journal of Composites for Construction, 18: 04014009.

Barros, J. A. O., and A. S. Fortes. 2005. 'Flexural strengthening of concrete beams with CFRP laminates bonded into slits', Cement and Concrete Composites, 27: 471-80.

Brückner, A., R. Ortlepp, and M. Curbach. 2006. 'Textile reinforced concrete for strengthening in bending and shear', Materials and Structures, 39: 741-48.

Capozucca, R. 2014. 'On the strengthening of RC beams with near surface mounted GFRP rods', Composite Structures, 117: 143-55.

Ebead, U. A. 2011. 'Hybrid externally bonded/mechanically fastened fiber-reinforced polymer for RC beam strengthening', ACI Structural Journal, 108: 1-10.

Ebead, U. A., and H Saeed. 2014. 'Flexural and interfacial behavior of externally bonded/mechanically fastened fiber-reinforced polymer strengthened reinforced concrete beams', ACI Structural Journal, 111: 741-51. 
Ebead, U. A., and H. Saeed. 2013. 'Hybrid shear strengthening system for reinforced concrete beams: An experimental study', Engineering Structures, 49: 421-33.

Elsayed, W. E, U. A Ebead, and K. W Neale. 2009. 'Studies on mechanically fastened fiber-reinforced polymer strengthening systems', ACI Structural Journal, 106: 49-59.

Elsayed, W. E., U. A. Ebead, and K. W. Neale. 2007. 'Interfacial Behavior and Debonding Failures in FRP-Strengthened Concrete Slabs', ASCE Journal of Composites for Construction, 11: 619-28.

ICC, Evaluation Service. 2013. Acceptance criteria for masonry and concrete strengthening using fiber reinforced cementitious matrix (FRCM) composite systems (AC434: Whittier, CA).

Kotynia, R., H. M. Abdel Baky, K. W. Neale, and U. A. Ebead. 2008. 'Flexural strengthening of RC beams with externally bonded CFRP systems: Test results and 3D nonlinear FE Analysis', ASCE Journal of Composites for Construction, 12: 190-201.

Kreit, A., F. Al-Mahmoud, A. Castel, and R. François. 2010. 'Repairing corroded RC beam with nearsurface mounted CFRP rods', Materials and Structures, 44: 1205-17.

Loreto, G., S. Babaeidarabad, L. Leardini, and A. Nanni. 2015. 'RC beams shear-strengthened with fabricreinforced-cementitious-matrix (FRCM) composite', International Journal of Advanced Structural Engineering (IJASE), 7: 341-52.

Neale, K. W., U. A. Ebead, H. M. Abdel Baky, W. E. Elsayed, and A. Godat. 2006. 'Analysis of the load-deformation behaviour and debonding for FRP-strengthened concrete structures', Advances in Structural Engineering, 9: 751-63.

Ombres, L. 2015. 'Structural performances of reinforced concrete beams strengthened in shear with a cement based fiber composite material', Composite Structures, 122: 316-29.

Ombres, L. 2011. 'Flexural analysis of reinforced concrete beams strengthened with a cement based high strength composite material', Composite Structures, 94: 143-55.

Teng, J. G., L. De Lorenzis, Bo Wang, Rong Li, T. N. Wong, and Lik Lam. 2006. 'Debonding failures of RC beams strengthened with near surface mounted CFRP strips', ASCE Journal of Composites for Construction, 10: 92-105.

Tetta, Z. C., L. N. Koutas, and D. A. Bournas. 2015. 'Textile-reinforced mortar (TRM) versus fiberreinforced polymers (FRP) in shear strengthening of concrete beams', Composites Part B: Engineering, 77: 338-48.

Trapko, T. 2014. 'Effect of eccentric compression loading on the strains of FRCM confined concrete columns', Construction and Building Materials, 61: 97-105.

Triantafillou, T. C., and C. G. Papanicolaou. 2006. 'Shear strengthening of reinforced concrete members with textile reinforced mortar (TRM) jackets', Materials and Structures, 39: 93-103. 